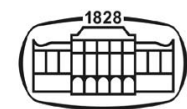

AKADÉMIAI KIADÓ

Acta Microbiologica et Immunologica Hungarica

67 (2020) 1, 18-22

DOI: $10.1556 / 030.66 .2019 .028$

(c) 2019 Akadémiai Kiadó, Budapest

\title{
Emergence of colistin-resistant Klebsiella pneumoniae in Poland
}

\section{ALICJA SĘKOWSKA*, MICHA£ CHUDY and EUGENIA GOSPODAREK-KOMKOWSKA}

Department of Microbiology, Ludwik Rydygier Collegium Medicum, Nicolaus Copernicus University, Bydgoszcz, Poland

Received: May 10, 2019 • Accepted: July 12, 2019 • Published online: December 09, 2019

\section{ORIGINAL ARTICLE}

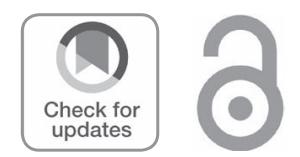

* Corresponding author: Alicja Sękowska

Department of Microbiology, Ludwik Rydygier Collegium Medicum, Nicolaus Copernicus University, $9 \mathrm{M}$. Sklodowska-Curie Street, 85-094 Bydgoszcz, Poland Phone: +48 5258534 81; Fax: +48 525854480 E-mail: asekowska@cm.umk.pl

\section{ABSTRACT}

In recent years, colistin has been the drug of choice for treatment of nosocomial infections, especially in bloodstream infections, lower respiratory tract infections, or urinary tract infections. In this study, 65 multidrug-resistant Klebsiella pneumoniae isolated from different clinical samples were included. Minimum inhibitory concentration (MIC) of colistin was detected by broth microdilution method in three different ways. For selected K. pneumoniae strains, eazyplex SuperBug mcr-1 test was performed. This test detects $m c r-1$ gene, which encodes a colistin-resistance determinant. Most of the analyzed $K$. pneumoniae strains were resistant to colistin in all applied methods. The exception was two strains, where MIC of colistin was $2 \mathrm{mg} / \mathrm{L}$ in SensiTest Colistin and MIC-Strip Colistin tests. In MIC COL test, MIC for these strains was $4 \mathrm{mg} / \mathrm{L}$. All analyzed strains produced extended-spectrum beta-lactamases and 11 (16.9\%) metallo-beta-lactamases. Eleven (16.9\%) K. pneumoniae strains were resistant to all antibiotics, whereas 17 (26.1\%) were susceptible to only one drug. Colistin MIC values varied from 2 to $>64 \mathrm{mg} / \mathrm{L}$ in MIC-Strip Colistin test; from 2 to $>16 \mathrm{mg} / \mathrm{L}$ in SensiTest Colistin and from 4 to $>16 \mathrm{mg} / \mathrm{L}$ in MIC COL test. None of the analyzed K. pneumoniae strains carried $\mathrm{mcr}-1$ gene. Data of this work suggest that resistance to colistin emerged among multidrug-resistant K. pneumoniae strains. The tests allowed for reliable estimation of susceptibility to colistin and could be used in microbiological diagnostics.

\section{KEYWORDS}

susceptibility, colistin, detection of resistance, Klebsiella pneumoniae, mcr-1 gene

\section{INTRODUCTION}

Klebsiella spp. are among frequent bacteria causing hospital infections. These bacteria easily acquire resistance to antibiotics, and one strain can produce several mechanisms of resistance; therefore, colistin often remains as the only therapeutic option. The most common mechanism of antibiotic resistance in Klebsiella pneumoniae is the production of the extended-spectrum beta-lactamases (ESBLs). The first ESBL-positive strain was detected more than 30 years ago, but these enzymes and their constant evolution remain a significant therapeutic problem. In Poland, ESBLs range from $40 \%$ to $70 \%$ depending on the regional location, type of ward/hospital, and species of bacteria [Żabicka, unpublished data]. In our hospital, above $60 \%$ of the K. pneumoniae strains produced ESBLs. In the past years, strains producing carbapenemases were more often isolated. In Poland, the predominant carbapenemases are NDM and VIM. According to the data of the European Antimicrobial Resistance Surveillance System [1] in Poland, the percentage of K. pneumoniae strains resistant to carbapenems increased from $1 \%-5 \%$ in 2015 to $5 \%-<10 \%$ in 2017 . In our hospital, $2 \%-3 \%$ of the K. pneumoniae strains produced carbapenemases. Strains producing carbapenemases are often susceptible only to colistin. At present, in Poland, Enterobacteriaceae strains resistant to colistin are rarely $1 \%-2 \%$ (Żabicka, unpublished data).

Colistin was discovered in 1940s. This drug is a polycationic antibiotic peptide and is active only against Gram-negative rods. Because of neurotoxicity and nephrotoxicity, it was not used 
in treatment of infections, but irrational use of common antibiotics and more frequent emergence of carbapenemresistant strains have made it the most frequent use of drug as last choice. Colistin resistance may result from chromosomal mutations that cause change in the external lipopolysaccharide (modification of lipid A). This modification decreases the negative charge of the outer membrane, reducing its interaction with colistin [2]. In K. pneumoniae strains, resistant to colistin chromosomal mutations occurs in the $m g r \mathrm{~B}$ (deactivation of lipid A), $p m r \mathrm{E} p b g \mathrm{P}, p m r \mathrm{C}, p a g \mathrm{P}$ (neutralization of lipid A), pmrB (overexpression of lipid A), lp $x \mathrm{M}$ (maturation of lipid A), pho $\mathrm{P} / p h o \mathrm{Q}, p m r \mathrm{~A}, p m r \mathrm{C}$, and $c r r A B C$ genes [3-5]. The most common chromosomal gene mutations occur in $m g r B$ [6]. Colistin resistance could be associated with horizontal transfer of the $\mathrm{mcr}$ gene. The mor gene was discovered in China in E. coli and K. pneumoniae strains isolated from human and animals [7]. The resistance associated with the $\mathrm{mor}$ gene is mainly plasmid coded. At present, it is estimated that the $m c r$ gene is present in eight variants from $m c r-1$ to $m c r-8$, but the $m c r-1$ is the most predominant gene $[6,8-11]$. The $m c r-1$ gene encodes a phosphoethanolamine transferase enzyme family and modifies lipid A [5]. Other strategies for colistin resistance include the utilization of an efflux pump AcrAB and capsule synthesis $[4,12]$. Capsule polysaccharides may mask charged molecules on the outer membrane and an increased expression of efflux pumps AcrAB-TolC and KpnEF confers colistin resistance [5]. In turn, Helander et al. [13] observed a greater degree of acylation in K. pneumoniae strains resistant to colistin.

Thus, the aim of this study was to evaluate and compare selected methods of resistance to colistin of K. pneumoniae strains.

\section{MATERIALS AND METHODS}

\section{Strain collection}

Strains were collected within 4 months in 2017 from patients in Dr. A. Jurasz University Hospital in Bydgoszcz (Poland). During this period, $321 \mathrm{~K}$. pneumoniae strains were isolated, of which $65(20.2 \%)$ were resistant to colistin. The study included 65 non-replicate K. pneumoniae strains isolated from clinical samples. The analyzed strains were isolated from different specimens: bronchoalveolar lavage (21), blood (16), wound swabs (8), urine (8), and biomaterials (2). Ten (15.4\%) strains were isolated from colonization: rectal swabs, throat swabs, and stool. The multidrug resistance strains were selected for this study. Eighteen $(27.7 \%)$ patients from whom K. pneumoniae strains had been isolated were treated with colistin. Fifteen (23.0\%) patients were not treated with antibiotics. The strains were identified by matrix-assisted laser desorption ionization-time of flight mass spectrometry (Bruker, Billerica, USA). The susceptibility to antibiotics was tested by automated method in Phoenix system using NMIC-402 cart (Becton-Dickinson, New Jersey, USA).

\section{Phenotypic detection of beta-lactam resistance}

A double disk synergy test was performed for K. pneumoniae strains to detect ESBLs [14]. The ability to produce metallo-beta-lactamases (MBLs) was determined by Carba NP test [15] and double disk synergy test with ethylenediaminetetraacetic acid. Both tests were performed in accordance with the recommendations of National Centre for Susceptibility Testing [16].

\section{Phenotypic detection of colistin resistance}

Minimum inhibitory concentration (MIC) of colistin was determined by microdilution method applying three different tests: SensiTest Colistin (Liofilchem, Via Scozia, Italy) [17-19], MIC-Strip (Merlin, Berlin, Germany) [18, 19], and MIC COL (Diagnostics, Brno, Czech Republic) $[19,20]$. Colistin MICs ranged from 0.25 to $16 \mathrm{mg} / \mathrm{L}$ in SensiTest Colistin and MIC COL tests and from 0.0625 to $64 \mathrm{mg} / \mathrm{L}$ in MIC-Strip test.

\section{Molecular detection of colistin resistance}

For selected strains, eazyplex ${ }^{\circledR}$ SuperBug CRE test (Amplex Diagnostics, Gars AM Inn, Germany) was carried out. This test is based on the loop mediated isothermal amplification method (LAMP), and can detect gene encoding resistance to colistin associated with $m c r-1$ gene [18].

Escherichia coli NCTC 13440 (colistin-resistant, mcr-1 positive) was used as positive control strain.

\section{RESULTS}

All analyzed K. pneumoniae strains produced ESBL. Eleven (16.9\%) K. pneumoniae strains produced MBLs. These strains were resistant to all antibiotics. Seventeen (26.1\%) strains were susceptible only to one drug, tigecycline, imipenem, or gentamicin. Twenty-two (33.9\%) strains were susceptible to carbapenems (imipenem and meropenem). The results of susceptibility to selected antibiotics are presented in Table I. Other K. pneumoniae strains were susceptible to imipenem, meropenem, and tigecycline. Among analyzed $K$. pneumoniae strains $\mathrm{MIC}_{50}$ was $16 \mathrm{mg} / \mathrm{L}$, and $\mathrm{MIC}_{90}$ was $16 \mathrm{mg} / \mathrm{L}$ in SensiTest Colistin and MIC COL tests, respectively. In MIC-Strip test, value of $\mathrm{MIC}_{50}$ was $16 \mathrm{mg} / \mathrm{L}$ and $\mathrm{MIC}_{90}$ was $32 \mathrm{mg} / \mathrm{L}$. MICs for colistin in SensiTest Colistin ranged from 2 to $>16 \mathrm{mg} / \mathrm{L}$; in MIC-Strip test from 1 to $>64 \mathrm{mg} / \mathrm{L}$, and in MIC COL from 4 to $>16 \mathrm{mg} / \mathrm{L}$. The results of colistin MICs are presented in Table II. The MIC values for colistin were highest for strains isolated from patients treated with this drug.

\section{DISCUSSION}

In recent years, strains resistant to all available drugs have been increasingly isolated. This is due to the excessive and 
Table I. Susceptibility to selected antimicrobials of $K$. pneumoniae strains $(n=65)$

\begin{tabular}{|l|c|c|c|c|}
\hline Imipenem & Meropenem & Gentamicin & Tigecycline & No. (\%) of strains \\
\hline Susceptible & Susceptible & Resistant & Resistant & $22(33.9)$ \\
\hline Susceptible & Susceptible & Resistant & Susceptible & $15(23.1)$ \\
\hline Resistant & Resistant & Resistant & Resistant & $11(16.9)$ \\
\hline Susceptible & Resistant & Resistant & Resistant & $10(15.4)$ \\
\hline Resistant & Resistant & Resistant & Susceptible & $4(6.1)$ \\
\hline Resistant & Resistant & Susceptible & Resistant & $3(4.6)$ \\
\hline
\end{tabular}

Table II. Colistin MIC values of K. pneumoniae strains $(n=65)$

\begin{tabular}{|l|c|c|c|}
\hline \multirow{2}{*}{$\begin{array}{l}\text { Colistin MIC } \\
(\mathrm{mg} / \mathrm{L})\end{array}$} & $\begin{array}{c}|c| \\
\text { NonsiTest } \\
\text { Colistin } \\
\text { (Liofilchem) }\end{array}$ & $\begin{array}{c}\text { MIC-Strip } \\
\text { (Merlin) }\end{array}$ & $\begin{array}{c}\text { MIC COL } \\
\text { (Diagnostics) }\end{array}$ \\
\hline$>64$ & - & 13 & - \\
\hline 64 & - & 8 & - \\
\hline 32 & - & 14 & - \\
\hline$>16$ & 43 & - & 27 \\
\hline 16 & 5 & 16 & 22 \\
\hline 8 & 10 & 7 & 10 \\
\hline 4 & 5 & 3 & 6 \\
\hline 2 & 2 & 4 & - \\
\hline
\end{tabular}

Note: MIC: minimum inhibitory concentration.

uncontrolled use of antibiotics, but also the high epidemic potential of multidrug-resistant strains. Since the discovery of the first K. pneumoniae ESBL-positive strain in 1983, resistance to subsequent antibiotics has progressed quickly. In particular, the emergence of carbapenem-resistant strains made this situation even worrisome; therefore, therapy options returned to "old-fashion" drugs.

Colistin was isolated from Paenibacillus polymyxa subsp. colistinus in 1947 [21]. For many years, it was discontinued in clinical practice due to its high toxicity. In the era of multidrug resistance, however, a return to its use is observed. Therefore, the appearance of colistin-resistant strains is disturbing, because there are no effective antibacterial therapies available.

The incidence of acquired colistin-resistant strains among Enterobacteriaceae varies widely and ranges from $1 \%$ [22] to $15.9 \%$ [20]. Qamar et al. [20], when assessing the MIC of colistin against strains of the Enterobacteriaceae family, obtained $\mathrm{MIC}_{50}-0.5 \mathrm{mg} / \mathrm{L}$ and $\mathrm{MIC}_{90}-16 \mathrm{mg} / \mathrm{L} . \mathrm{K}$. pneumoniae strains were accounting for over $50 \%$ of the tested strains. All analyzed strains produced carbapenemases. In turn, Galani et al. [23] reported $\mathrm{MIC}_{50}-1 \mathrm{mg} / \mathrm{L}$ and $\mathrm{MIC}_{90}>16 \mathrm{mg} / \mathrm{L}$. They used SensiTest Colistin (Liofilchem). Obtained results in this test were higher for $\mathrm{MIC}_{50}-16 \mathrm{mg} / \mathrm{L}$. Bosacka et al. [19] reported categorical agreements for $96.1 \%$ of analyzed Gram-negative strains in SensiTest colistin (Liofilchem), 94.1\% in MIC-Strip (Merlin), and 93.1\% - MIC COL (Diagnostics). In turn, Sekyere [18] obtained categorical agreements for $89.0 \%-98.9 \%$ of analyzed Enterobacteriaceae and non-fermenter rods in SensiTest colistin (Liofilchem) and $91.0 \%$ in MIC-Strip (Merlin). In the presented work, three different tests were applied using the broth microdilution method for determining the sensitivity to colistin. At present, this method is recommended by EUCAST. In all tests, the results were similar. Differences were observed in two strains, where the MIC values were different, which affected the interpretation. Sensitive result was obtained in SensiTest Colistin and MIC-Strip tests (MIC was $2 \mathrm{mg} / \mathrm{L}$ ) and resistant MIC COL test (MIC $4 \mathrm{mg} / \mathrm{L}$ ). The broth microdilution tests are simple and relatively cheap [18]. At work, almost $28 \%$ of patients were previously treated with colistin, so colistin therapy is an important risk factor for acquiring resistance to this drug.

None of the tested strains carried the $m c r-1$ gene; therefore, resistance to colistin was probably related to chromosomal mutations. Casselli et al. [24], when estimating the presence of $m c r-1$ gene, obtained $8.3 \%$ of Enterobacteriaceae strains. In turn, Sekyere [18] reported $100 \%$ sensitivity and $100 \%$ specificity using eazyplex ${ }^{\circledast}$ SuperBug CRE test. The author examined 104 strains of Enterobacteriaceae family. Eazyplex ${ }^{\circledast}$ SuperBug CRE test is simple to perform and short, but expensive.

The emergence of multidrug-resistant strains often leads to difficult choices regarding antibiotic therapy. Limited or no therapeutic options force the use of drugs with reduced susceptibility, non-standard combination therapies, or increasing the dose of the drug. Therefore, it is necessary to monitor the emergence of resistant strains and rapid detection of resistance to colistin. 
Acknowledgements: This research was financially supported by the Nicolaus Copernicus University funds for the maintenance of the research potential of the Department of Microbiology.

Conflict of Interest: The authors declare no conflict of interest.

\section{REFERENCES}

1. EARSS: West Nile virus infection. Available at http:// ecdc.europa.eu

2. Velkov, T., Deris, Z. Z., Huang, J. X., Azad, M. A. K., Butler, M., Sivanesan, S., Kaminskas, L. M., Dong, Y. D., Boyd, B., Baker, M. A., Cooper, M. A., Nation, R. L., Li, J.: Surface changes and polymyxin interactions with a resistant strain of Klebsiella pneumoniae. Innate Immunol 20, 350-363 (2014).

3. Cannatelli, A., Giani, T., Antonelli, A., Principe, L., Luzzaro, F., Rossolini, G. M.: First detection of the $m c r-1$ colistin resistance gene in Escherichia coli in Italy. Antimicrob Agents Chemother 60, 3257-3258 (2016).

4. Olaitan, A. O., Diene, S. M., Kempf, M., Berrazeg, M., Bakour, S., Gupta, S. K., Thongmalayvong, B., Akkhavong, K., Somphavong, S., Paboriboune, P., Chaisiri, K., Komalamisra, C., Adelowo, O. O., Fagade, O. E., Banjo, O. A., Oke, A. J., Adler, A., Assous, M. V., Morand, S., Raoult, D., Rolain, J. M.: Worldwide emergence of colistin resistance in Klebsiella pneumoniae from health humans and patients in Lao PDR, Thailand, Israel, Nigeria and France owing to inactivation of the PhoP/PhoQ regulator mgrB: An epidemiological and molecular study. Int J Antimicrob Agents 44, 500-507 (2014).

5. Navon-Venezia, S., Kondratyeva, K., Carattoli, A.: Klebsiella pneumoniae: A major worldwide source and shuttle for antibiotic resistance. FEMS Microbiol Rev 41, 252-275 (2017).

6. Pragasam, A. K., Shankar, C., Veerarghavan, B., Biswas, I., Nabarro, L. E. B., Inbanathan, F. Y., George, B., Vergese, S.: Molecular mechanism of colistin resistance in Klebsiella pneumoniae causing bacteremia from India - A first report. Front Microbiol 7, 2135 (2017).

7. Liu, Y. Y., Wang, Y., Walsh, T. R., Yi, L. X., Zhang, R., Spencer, J., Doi, Y., Tian, G., Dong, B., Huang, X.: Emergence of plasmid-mediated colistin resistance mechanism MCR-1 in animals and human beings in China: A microbiological and molecular biological study. Lancet Infect Dis 16, 161-168 (2016).

8. Carattoli, A., Villa, L., Feudi, C., Curcio, L., Orsini, S., Luppi, A.: Novel plasmid-mediated colistin resistance mor-4 gene in Salmonella and Escherichia coli, Italy 2013, Spain and Belgium, 2015 to 2016. Euro Surveill 22, 30589 (2017).

9. Xavier, B. B., Lammens, C., Ruhal, R., Kumar-Singh, S., Butaye, P., Goossens, H.: Identification of a novel plasmid-mediated colistin-resistance gene, $\mathrm{mcr}$-2, in Escherichia coli, Belgium, June 2016. Euro Surveill 21, 30280 (2016).

10. Roer, L., Hansen, F., Stegger, M., Sönksen, U. W., Hasman, H., Hammerum, A. M.: Novel mcr-3 variant, encoding mobile colistin resistance, in an ST131 Escherichia coli isolate from bloodstream infection, Denmark, 2014. Euro Surveill 22, 30584 (2017).

11. Wang, X., Wang, Y., Zhou, Y., Li, J., Yin, W., Wang, S., Zhang, S., Shen, J., Shen, Z., Wang, Y.: Emergence of a novel mobile colistin resistance gene, $m c r-8$, in NDM-producing Klebsiella pneumoniae. Emerg Microbes Infect 7, 122 (2018).

12. Padilla, E., Llobet, E., Domenech-Sanchez, A., MartinezMartinez, L., Bengoechea, J. A., Alberti, S.: Klebsiella pneumoniae AcrB efflux pump contributes to antimicrobila resisatnce and virulence. Antimicrob Agents Chemother 54, 177-183 (2010).

13. Helander, I. M., Kato, Y., Kilpelainen, I, Kostainen, R., Lindner, B., Nummila, K.: Characterization of lipopolisaccharides of polymyxin-resistant and polymyxin-sensitive Klebsiella pneumoniae O3. Eur J Biochem 237, 272-278 (1996).

14. Jarlier, V., Nicolas, M. H., Fournier, G., Philippon, A.: Extended broad-spectrum $\beta$-lactamases conferring resistance to newer $\beta$-lactam agents in Enterobacteriaceae: Hospital prevalence and susceptibility patterns. Rev Infect Dis 10, 867-878 (1998)

15. Nordmann, P., Poirel, L., Dortet, L.: Rapid detection of carabapenemase-producing Enterobacteriaceae. Emerg Infect Dis 18, 1503-1507 (2012)

16. Narodowy Program Ochrony Antybiotykow: Zalecenia dotyczące postępowania w przypadku zachorowań sporadycznych i ognisk epidemicznych wywoływanych przez Gram-ujemne pałeczki z rodziny Enterobacteriaceae. Zalecenia Ministra Zdrowia dotyczące postępowania w przypadku identyfikacji szczepów bakteryjnych Enterobacteriaceae wytwarzających karbapenemazy typu KPC, MBL lub OXA-48 [National Antibiotic Protection Program: Recommendations for sporadic cases and epidemic outbreaks cause by Enterobacteriaceae rods. Recommendations of the Minister of Health. Enterobacteriaceae producing carbapenemases: KPC, MBL or OXA-48]. Available at http://www.antybiotyki.edu.pl

17. Izdebski, R., Baraniak, A, Bojarska, K., Urbanowicz, P., Fiett, J., Pomorska-Wesołowska, M., Hryniewicz, W., Gniadkowski, M., Żabicka, D.: Mobile mcr-1-associated resistance to colistin in Poland. J Antimicrob Chemother 71, 2331-2333 (2016).

18. Sekyere, J. O.: Mcr colistin resistance gene: A systematic review of current diagnostics and detection methods. Microbiologyopen 8, e00682 (2019).

19. Bosacka, K., Kozińska, A., Stefaniuk, E., Rybicka, J., Mikołajczyk, A., Młodzińska, E., Hryniewicz, W.: Colistin antimicrobial susceptibility testing of Gram-negative bacteria - Evaluation of test available in Poland. In 28th ECCMID, Madrid Spain, E0116, 2018.

20. Qamar, S., Shaheen, N., Shakoor, S., Farooqi, J., Jabeen, K., Hasan, R.: Frequency of colistin and fosfomycin resistance in carbapenem-resistant Enterobacteriaceae from a tertiary care hospital in Karachi. Infect Drug Resist 10, 231-236 (2017).

21. Poirel, L., Jayol, A., Nordmann, P.: Polymyxins: Antibacterial activity, susceptibility testing, and resistance mechanisms encoded by plasmids or chromosomes. Clin Microb Rev 30, 557-596 (2017).

22. Saavedra, S. Y., Diaz, L., Wiesner, M., Correa, A., Arevalo, S. A., Reves, J., Hidalgo, A. M., de la Cadena, E., Perenguez, M., Montano, L. A.: Genomic and molecular characterization of 
clinical isolates of Enterobacteriaceae harboring $m c r-1$ in Colombia, 2002 to 2016. Antimicrob Agents Chemother 61, pii: e00841-17 (2017).

23. Galani, I., Adamou, P., Karaikos, I., Giamarellou, H., Souli, M.: Evaluation of ComASPTM Colistin (formerly SensiTest ${ }^{\mathrm{TM}}$ Colistin), a commercial broth microdilution-based method to evaluate the colistin minimum inhibitory concentration for carbapenem-resistant Klebsiella pneumoniae isolates. J Glob Antimicrob Resist 15, 123-126 (2018).

24. Casselli, E., D’Accolti, M., Soffritti, I., Piffanelli, M., Mazzacane, S.: Spread of mcr-1-driven colistin resistance on hospital surfaces, Italy. Emerg Infect Dis 24, 1752-1753 (2018). 